\title{
IMPASSES TEÓRICO-METODOLÓGICOS NO CAMPO DA FORMAÇÃO INICIAL DE PROFESSORES E SUAS IMPLICAÇÕES 7NA FORMAÇÃO DOS LICENCIANDOS NO CONTEXTO BRASILEIRO ATUAL
}

Kally Samara Silva Medeiros Gomes ${ }^{(*)}$ Lenilda Rêgo Albuquerque de Faria ${ }^{(* *)}$

\section{INTRODUÇÃO}

A formação de professores tem sido um tema que ganhou expressiva notoriedade no cenário educacional brasileiro nos últimos anos. Isso é observado tanto nas políticas públicas, quanto nas produções acadêmicas da área da Educação. Contudo, pode-se enfatizar que no contexto das reformas neoliberais a ênfase recai nos processos de formação inicial de professores, ou seja, nas licenciaturas.

Como se sabe, no cenário brasileiro a reestruturação produtiva e a globalização da economia são fatores determinantes do novo padrão de acumulação do capital, que introduzem grande dinamicidade às mudanças que ocorrem no processo produtivo, assim os desdobramentos dessa influência se estendem para todas as instituições sociais, inclusive para as de educação, atingindo consequentemente o campo da formação de professores, que vai se edificando sob a égide dos princípios centrais de controle, previsão e ação eficiente.

Assim sendo, a busca pelo estudo dos modelos da formação de professores e seus desdobramentos é basilar no sentido de permitir o entendimento da sociedade e seus movimentos, uma vez que as ações adotadas em cada contexto respaldam o processo de formação de professores de diferentes épocas.

Nesse prisma, o objetivo deste artigo é apresentar um estudo sobre os impasses teóricometodológicos no campo da formação inicial de professores e suas implicações na formação dos licenciandos, no contexto brasileiro atual.

\footnotetext{
${ }^{(*)}$ Mestra em Educação pelo Programa de Pós-Graduação em Educação da Universidade Federal do Acre. Professora do Instituto Federal da Paraíba (IFPB).

${ }^{(* *)}$ Doutora em Educação; docente no Programa de Pós-Graduação em Educação da Universidade Federal do Acre. Professora Adjunta na Universidade Federal do Acre. Coordenadora do GT de Didática da Anped, 2017/2019,
} 


\section{DOS CAMINHOS METODOLÓGICOS}

O presente artigo resulta de uma pesquisa bibliográfica de enfoque qualitativo, centrado em referenciais teóricos e resultados de pesquisas, que analisaram a formação inicial de professores no atual contexto brasileiro.

Segundo Severino (2007), a pesquisa bibliográfica é aquela que se realiza a partir do:

[...] registro disponível, decorrente de pesquisas anteriores, em documentos impressos, como livros, artigos, teses etc. Utilizam-se dados de categorias teóricas já trabalhadas por outros pesquisadores e devidamente registrados. Os textos tornam-se fontes dos temas a serem pesquisados. O pesquisador trabalha a partir de contribuições dos autores dos estudos analíticos constantes dos textos (SEVERINO, 2007, p.122).

Desse modo, para atingir o objetivo proposto neste trabalho, recorreu-se a revisão de literatura no campo da formação inicial de professores na intenção de contextualizar a temática estudada. Após esse processo, foi feito um recorte com foco na formação do licenciando, objetivando saber, os contornos que vem assumindo no atual contexto brasileiro. Foram fundamentais para este estudo as análises de Antunes (2002); Faria (2011); Freitas (1996; 2014); Frigotto (2010); Libâneo (2010); Marx (2006); Oliveira (2004; 2013); Paulo Netto e Braz (2006); Pimenta (1997; 2002; 2010); Saviani (2007; 2009; 2011) e Severino (2001; 2004; 2007).

\section{TRABALHO E EDUCAÇÃO: BASES ONTOLÓGICAS DA EXISTÊNCIA HUMANA E SUA MUDANÇA DE SENTIDO NA ORDEM DO CAPITAL}

Antes de enfatizar o trabalho como categoria fundante de transformação da natureza e constituição do ser social, se faz necessário compreender que ele não se reduz a um "fator" isolado no interior de uma sociedade, como é defendido na perspectiva neoliberal. Segundo Frigotto (2010), nessa visão liberal clássica, a sociedade é constituída por fatores (economia, educação, trabalho, tecnologia, religião, dentre outros) onde, em um determinado período, um deles torna-se fundamental e determinante. No entanto, na perspectiva histórica de análise marxista, a realidade social é concebida como uma totalidade de relações, que condiciona a vida social em conjunto.

Nessa linha de raciocínio, Faria (2011), esclarece que,

[...] o homem, pela prática social, na tessitura da realidade, manifesta-se em uma totalidade de dimensões articuladas, não existe sozinho, solto. [...], não há, portanto, uma hierarquia entre as esferas do ser social, pois, essas são modalidades distintas que atendem a necessidades também distintas do ser. Essas necessidades se imbricam, se articulam em uma relação de reciprocidade, alterando-se continuamente; porém não é 
uma ligação por justaposição, mas por mediação da práxis humano-social, que ora vai do particular ao universal, ora desse àquele constituindo-se uma totalidade concreta. (p. $54)$.

Com base neste entendimento, pode-se dizer que o trabalho em articulação com outras esferas do ser social é a condição básica e fundamental de toda vida humana. Assim, afirma Frigotto (2010), o trabalho é por excelência, a forma mediante a qual o homem produz suas condições de existência, a história, o mundo propriamente humano, ou seja, o próprio ser humano. Para Marx (1983),

[...] a categoria trabalho é um processo entre o homem e a natureza, um trabalho em que o homem, por sua própria ação, media, regula e controla seu metabolismo com a natureza. [...]. Pressupomos o trabalho numa forma em que pertence exclusivamente ao homem. [...]. Mas o que distingue, de antemão, o pior arquiteto da melhor abelha é que ele constitui o favo, em sua cabeça, antes de construí-lo em cera. No final do processo de trabalho obtêm-se um resultado que já no início deste existiu na imaginação do trabalhador, e portanto, idealmente. [...]. (PAULO NETTO; BRAZ, 2006. p. 31).

Nesse sentido, o trabalho é considerado como uma atividade exclusivamente humana, a partir do momento que sua ação é projetada, ou seja, é teleologicamente direcionada para se atingir um determinado fim. Para fundamentar essa afirmação, outro elemento se insere nesse contexto, a linguagem articulada, também necessária para se fazer expressar as representações do homem e do mundo que o cerca.

Assim, como dito anteriormente, o trabalho não é um processo que se desenvolve isoladamente, consequentemente seu sujeito não é isolado, porque sempre se insere num conjunto de outros sujeitos. Logo, o caráter coletivo da atividade do trabalho é consubstancialmente, o que caracteriza o sujeito como um ser social. Segundo Paulo Netto e Braz (2006),

[...], o surgimento da espécie humana não configura uma necessidade da evolução biológica nem o desdobramento de uma programação genética: foi uma autêntica ruptura nos mecanismos e regularidades naturais, uma passagem casual como a da natureza inorgânica à orgânica e foi precedida, certamente, de modificações ocorrentes numa escala temporal de largo curso. A espécie humana desenvolve-se como um outro novo tipo de ser, até então inexistente, e cujas peculiaridades não se devem à herança biológica nem a condições genéticas predeterminadas. (p. 36).

Nessa perspectiva, compreende-se que o trabalho foi a condição básica para os membros da espécie humana tornarem-se seres, isso implica dizer que a partir de uma base natural, os homens produziram-se a si mesmo, tornando-se seres sociais. Ainda na concepção desses autores, o 
desenvolvimento do ser social pode ser descrito como o processo de humanização dos homens, processo através do qual as determinações naturais, sem deixar de existir, jogam um papel cada vez menos relevante na vida humana. Portanto, quanto mais se torna ser social, menos o ser natural é determinante em sua vida. Sendo assim, quanto mais se desenvolve o ser social, mas diversificada serão suas objetivações, consequentemente haverá um avanço no processo de humanização desse ser.

Nessa amplitude, pode-se entender que a humanidade vem se desenvolvendo a medida que também se desenvolve seu sistema de objetivação, ao conjunto dessas objetivações está reservado a categoria da práxis. E como a práxis, conforme Faria (2011), "é a esfera da ação específica do homem" (FARIA, 2011, p. 52), é na práxis que seu produto torna-se criação de sua autoatividade, porém essa ação também pode produzir objetivações contrárias aos homens, na medida que ele não se reconheça como autoprodutores e criativos do seu produto, ou seja, que seu trabalho se apresente como algo que lhe é estranhado e opressivo.

Essa inversão segundo Paulo Netto e Braz (2006), caracteriza-se como o fenômeno histórico da alienação, própria de sociedades onde há divisão social do trabalho, onde o produto da atividade do trabalhador é expropriado, onde existem formas determinadas de exploração do homem pelo homem.

De acordo com as análises de Marx (2006),

[...], o estranhamento do trabalhador em seu objeto se expressa, pelas leis nacionaleconômicas, em que quanto mais o trabalhador produz, menos tem para consumir; que quanto mais valores cria, mais sem-valor e indigno ele se torna; quanto mais bem formado o seu produto, tanto mais deformado ele fica [...]. (p. 82).

Antunes (2002) ao se debruçar sobre as configurações de vigência do trabalho nas formas contemporâneas de estranhamento esclarece que, qualquer que seja o exercício do trabalho, seja pelo exercício laborativo manual ou imaterial, ambos, são controlados pelo sistema de metabolismo societal do capital e o estranhamento desses trabalhos encontram-se em sua essência. Isso torna-se visível, por exemplo, quando a necessidade de pensar, agir e propor dos trabalhadores leva sempre em conta prioritariamente os objetivos intrínsecos da empresa. Sendo assim, diz Antunes (2002), a subjetividade que emerge na fábrica ou nas esferas produtivas contemporâneas é expressão de uma existência inautêntica e estranhada pelos trabalhadores. Ao analisar as diferentes formas de estranhamento (de alienação) Jonh Holloway (1997) enfatiza que,

[...]. Se a humanidade é definida como atividade - pressuposto básico de Marx - então alienação significa que a humanidade existe sob a forma de inumanidade, que os sujeitos 
humanos existem como objetos. Alienação é a objetivação do sujeito. O sujeito (homem ou mulher) aliena sua subjetividade, e essa subjetividade é apropriada por outros [...]. Ao mesmo tempo, como o sujeito é transformado em objeto, o objeto que o sujeito produz, o capital, é transformado no sujeito da sociedade. A objetivação do sujeito implica também a subjetificação do objeto. (apud ANTUNES, 2002. p. 132).

Isso acontece segundo este autor, na medida que a discursiva das esferas produtivas conta com maior "participação" dos trabalhadores nos projetos que nascem das discussões dos circuitos de controle de qualidade, demandando maior "envolvimento" por parte deles, assim, a subjetividade que então se manifesta encontra-se estranhada em relação ao que se produz e para que se produz.

Com base nesse contexto, Paulo Netto e Braz (2006) enfatizam que só uma sociedade onde todos os homens disponham das mesmas condições de sociabilização (uma sociedade sem exploração e sem alienação) pode oferecer a todos e a cada um as condições para que desenvolvam diferencialmente sua personalidade.

No entanto, até hoje o desenvolvimento do ser social jamais se expressou como o igual desenvolvimento da humanização de todos os homens, ao contrário, até os dias de hoje, o preço do desenvolvimento do ser social tem sido uma humanização extremamente desigual, ou seja, o processo de humanização tem custado o sacrifício da maioria dos homens. Essa realidade poderá ser modificada a partir do momento que a divisão social do trabalho e a propriedade privada dos meios de produção forem superadas, assim, pode-se pensar na possibilidade do desenvolvimento do ser social, de forma acessível a todos os homens.

$\mathrm{Na}$ busca de compreender o estreito vínculo ontológico-histórico da relação entre trabalho e educação, Saviani (2007) explicita que se a existência humana não é garantida pela natureza, isso significa dizer que o homem não nasce homem, e sim forma-se homem, a medida que ele não nasce sabendo produzir-se homem. Assim sendo, ele necessita aprender a ser homem, ou seja, precisa aprender a produzir sua própria existência. Logo, a produção do homem, é ao mesmo, a formação do homem, isto é, um processo educativo.

Para Severino (2001), “a educação é substantivamente mediação fundamental para as demais mediações pelas quais a existência histórica dos homens se constitui” (p. 1). Nesse sentido, para este autor, a educação é uma atividade prática como qualquer outra prática humana e como tal é forma de trabalho, é prática social e atividade cultural, pois é exatamente como mediação dessa articulação intencionalizante entre o conhecimento e as práticas históricas que se pode compreender a educação. Assim, a educação deve ser entendida como uma práxis humana cuja função intrínseca 
é a de mediar a existência histórica dos homens, mediando as práticas que constituem essa existência.

Segundo Saviani (2007), a origem da educação coincide, então, com a origem do homem, deste modo, a relação entre trabalho e educação é uma relação de identidade, a partir do momento que os homens aprendem a produzir sua existência no próprio ato de produzi-la, o que configura um verdadeiro processo de aprendizagem. Portanto, trabalho e educação são atividades especificamente humanas.

Vale ressaltar que nas comunidades primitivas a educação se dava pela participação simultânea, pelo exemplo e pela prática entre os homens, ou seja, eles apropriavam-se coletivamente dos meios de produção da existência, e nesse processo educavam-se e educavam as novas gerações. Tudo era feito em comum, não havia divisão de classes.

No entanto, ainda com base nas análises de Saviani (2007), pode-se dizer que no decorrer do tempo, os homens dividiram-se em classes distintas, e uma passou a sobreviver do trabalho da outra, devido a produção de excedentes, advindos da propriedade privada de terra e dos meios de produção. A partir daí o saber também passou a ser dividido de acordo com o que cada classe desempenhava na organização social. É nessa ocasião que surge a educação formal, a escola, como um lugar de transmissão desse saber para os filhos da classe que não precisava trabalhar e que desfrutava de tempo livre. Assim, a educação passa ser realizada numa perspectiva dualista, ou seja, uma educação voltada para o trabalho manual e outra destinada ao trabalho intelectual.

Com o surgimento do modo de produção capitalista a relação trabalho-educação sofreu uma nova determinação, originando uma reorganização das relações sociais. Nesse sentido, o impacto da Revolução Industrial pôs em questão a separação entre instrução e trabalho produtivo, forçando a escola a ligar-se ao mundo da produção. Dessa forma, o trabalho passou a orientar e determinar o caráter do currículo escolar em função das exigências da sociedade.

Para Freitas (1996),

[...] à medida que o modo de produção capitalista incorpora a ciência à máquina (como meio de produção), aumentam as exigências de ampliação das atividades intelectuais, havendo necessidade, portanto, de generalizar a educação escolar para todas as crianças, desde os níveis mais elementares, de modo a atender à formação da mão de obra necessária à produção $(\mathrm{p} .42)$.

Sob a égide do capital, a educação formal torna-se um lócus privilegiado para a reprodução das relações sociais alienadas. De tal modo que, a classe dominante passa a fazer da 
educação um espaço fecundo para a disseminação das suas ideias e interesses. Nesta sociedade, o trabalho é responsável por ajustar os indivíduos ao que é posto no âmbito da produção. O trabalhador expropriado dos meios de produção concebe com naturalidade a relação de exploração de uma classe sobre outra.

Nesse prisma, percebe-se que no bojo da sociedade capitalista a intenção não é proporcionar uma formação que contribua para o processo de humanização dos indivíduos numa perspectiva de inserção crítica e transformadora, mas uma educação voltada aos interesses do capital e que mantenha os trabalhadores presos às rédeas do sistema.

Em consonância com as análises de Saviani (2007) compreende-se que a natureza e especificidade da educação, atividade fundada pelo trabalho, constitui-se na transmissão de valores, habilidades e conhecimentos essenciais no processo de formação social do homem. Porém, na sociedade de classes, a educação desempenha, prioritariamente, a função social de atender as determinações da classe dominante em cada época histórica. Diante das circunstâncias destacadas, pode-se compreender que o sentido das categorias fundantes do ser social foi alterado à medida que as relações sociais capitalistas assumiram a forma predominante de sociedade.

O estudo apresentado nesta seção tem por objetivo expressar o entendimento das autoras sobre quais são as bases teórico-metodológica nas quais se originam os movimentos reflexivos e de sínteses realizados nessa pesquisa. Uma vez que compreender a formação de professores na raiz implica conhecer os condicionalismos sócio-políticos e culturais.

\section{OS IMPACTOS DAS REFORMAS NEOLIBERAIS NA FORMAÇÃO DE PROFESSORES NO BRASIL: UM BREVE APONTAMENTO}

A formação de professores tem sido um tema de destaque no cenário educacional brasileiro nos últimos anos. Isso é observado tanto por meio das políticas públicas, quanto nas produções acadêmicas, o que se pode atestar tanto pelo número de pesquisas que vem sendo realizadas, quanto pelo volume de trabalhos apresentados nos eventos científicos na área da Educação.

Como se sabe, desde as últimas décadas tem-se vivido momentos de reformulação do sistema educacional ajustados aos processos de reestruturação da própria sociedade em face da globalização e da imposição do mercado. Esses processos de reformas educativas e a implementação de novas políticas para a organização educacional brasileira, trazem modificações em termos de maior controle, menos autonomia para os professores e intensificação do trabalho realizado por eles. 
Assim, a discursiva em prol da qualidade da formação de professores como condição imperativa na busca de melhores resultados para o ensino tem sido intensa nos debates contemporâneos acerca do cenário educacional no Brasil.

Segundo Oliveira (2013), a busca pela melhoria da educação tem conduzido certas abordagens a colocar o professor como o principal responsável pela tarefa educativa, desviando o foco das estruturas e das relações sociais envolvidas nesse processo, reforçando assim, o alcance dos objetivos e metas previamente estabelecidos pelos gestores públicos. Assim sendo, as políticas educacionais demonstram estrategicamente essa preocupação ao situar o docente no centro do debate e a considerar que a formação de professores é a tática essencial para a melhoria da qualidade do ensino.

Por isso, se verifica que no contexto atual da sociedade neoliberal, a formação docente tem sido colocada em evidência, a partir do momento que essa preparação busca configurar um "novo" formato para os cursos de formação de professores, na perspectiva de produzir estrategicamente um professor, que se ajuste à lógica da reestruturação produtiva do trabalho diante do mundo globalizado.

Dessa maneira, os professores ganham centralidade nas reformas educacionais uma vez que são responsabilizados pela crise da educação e, ao mesmo tempo indicados como a alternativa para solucionar os problemas educacionais.

Segundo Oliveira (2004), essas reformas são marcadas por influências de organismos internacionais e regionais pertencentes à ONU em que a centralidade da educação é afirmada de modo imperativo para o desenvolvimento econômico, e, por conseguinte, confere-se importância estratégica à formação docente para a efetiva implementação das políticas educacionais.

Para Freitas (2014), estes atores, embora antigos, atuam nessa segunda onda neoliberal com maior força dentro dos órgãos nacionais de elaboração de políticas educacionais. Isso acontece ainda segundo este autor, na medida que os atuais reformadores empresariais, apenas retomam a filosofia pragmatista do começo do século passado, a partir de outros níveis de exigência tecnológica e de controle social e lhe dão aparência de "inovação", tratando novamente de adaptar a educação, mas especificamente a escola às exigências oriundas do mundo do trabalho e, em especial, ao aumento da produtividade de forma a recompor taxas de acumulação de riqueza.

Neste prisma, Frigotto (2010) destaca que

[...] Dentro desta 'nova ordem', os mesmos organismos internacionais (FMI, BID, BIRD, UNESCO, OIT, UNICEF, USAID), organismos regionais (CEPAL, 
CINTERFOR, OREALC), técnicos do Ministério da Educação e de instituições ligadas a formação técnica, empresários e mesmo pesquisadores que seguiam, desde o final da década de 1940, o receituário do CBAI para estabelecer os fatores responsáveis pela eficiência de formação para o trabalho ${ }^{1}$, a partir da década de 1960 passaram a obedecer o receituário do economicismo e tecnicismo veiculados pela teoria do capital humano [...]. Porém, nos anos de 1980 surgem novos conceitos e categorias, que aparentemente não superam aquelas perspectivas. [...], na verdade, trata-se de uma metamorfose de conceitos, sem todavia, alterar fundamentalmente as relações sociais que mascaram. (p. 58-59).

Nesse contexto, pode-se compreender que a teoria do capital humano metamorfoseado evoca que, no sistema neoliberal bruto e devorador, a educação surgi como uma forma de "humanizar" os indivíduos, mostrando-se como uma oportunidade de mudança individual e social.

Na lógica dessa teoria, a função da instituição de ensino perde a dimensão da formação humana e se restringe à qualificação de indivíduos para desenvolver a produção. Assim, a educação assume um papel de reprodução dos interesses do capital. Nessa direção, a formação de professores é encarada, portanto, por um viés mais utilitário e pragmático que emancipador, devendo caminhar no sentido de conduzir a educação básica para a satisfação das exigências do sistema produtivo no que tange à preparação de recursos humanos para potencializá-lo.

Vale ressaltar que os impactos dessas reformas afetam tanto a prática do professor-formador, quanto a formação inicial de professores, uma vez que, as competências profissionais, a postura do professor e os conhecimentos a serem construídos nessa formação passam a ser definidos de acordo com a escolha do paradigma de formação adotado em cada contexto social. Portanto, esse movimento paradigmático define também o modelo pedagógico adotado nos diferentes períodos históricos da sociedade.

Diante da atual conjuntura, Severino (2004) situa as deficiências dessa formação como uma das questões cruciais para os problemas que afetam a educação brasileira atualmente. Para o autor, o cenário dessas deficiências pode ser considerado a partir de três aspectos: o institucional, no que diz respeito às más condições do trabalho docente, à insuficiência dos recursos disponíveis e às condições das políticas de gestão; o pedagógico, considerando a fragilidade epistêmica, a carência de postura investigativa na formação docente e na insuficiência da prática no processo formativo,

\footnotetext{
${ }^{1}$ De acordo com Allen e Richars, os fatores responsáveis pela eficiência da formação técnico-profissional são: fator geral (conhecimentos gerais), manual (habilidades), específico (conhecimentos científicos básicos das noções tecnológicas), tecnológico (procedimentos técnicos), administrativo (capacidade de avaliar e organizar) e social (adaptação aos interesses da empresa e dos clientes) (FRIGOTTO, 2010, apud VIANNA, 1967).
} 
além da formação disciplinar, levando a visão de um mundo fragmentado, incapaz de dar conta da complexidade do trabalho docente; o ético-político, pois a formação não dá conta de desencadear no futuro professor a decisão ética de assumir o compromisso com a construção da cidadania. (SEVERINO, 2004. p. 17)

Libâneo (2010) também elenca uma série de entraves que pode estar comprometendo a formação de professores, quais sejam:

[...] ementas genéricas, retóricas da Didática e das metodologias específicas, mantendo ainda forte apoio no caráter instrumental; desarticulação entre conteúdos e metodologias; falta do conteúdo das disciplinas específicas a serem ensinadas nas escolas; pouca contribuição das disciplinas de -fundamentos da educação; às metodologias de ensino; grades curriculares e ementas que não mostram, no geral, unidade e integridade do projeto pedagógico [...] (p. 580).

Trata-se de questões que refletem o problema da separação entre teoria e prática no interior desses cursos de formação, evidenciando uma desarticulação na organização curricular e pedagógica dos mesmos, problema que carece de ser tensionado no debate mais amplo sobre a formação de professores no Brasil

Nessa perspectiva, Saviani (2011) afirma que durante dois séculos, a formação de professores revela um quadro de descontinuidade, embora sem rupturas, que até hoje não encontrou um encaminhamento satisfatório, porém o que se revela permanente é a precariedade das políticas formativas, cujas sucessivas mudanças não lograram estabelecer um padrão minimamente consistente de preparação docente para fazer face aos problemas enfrentados pela educação escolar em nosso país.

Nessa direção, esse autor apresenta os principais percalços que caracterizam a política de formação docente no contexto brasileiro atualmente, são eles:

a) fragmentação e dispersão das iniciativas, justificadas pela chamada "diversificação de modelos de organização da Educação Superior"; b) descontinuidade das políticas educacionais; c) burocratismo da organização e funcionamento dos cursos no qual o formalismo do cumprimento das normas legais se impõe sobre o domínio dos conhecimentos necessários ao exercício da profissão docente; d) separação entre as instituições formativas e o funcionamento das escolas no âmbito dos sistemas de ensino; e) o paradoxo pedagógico expresso na contraposição entre teoria e prática, entre conteúdo e forma, entre conhecimento disciplinar e saber pedagógico-didático (Cf. Capítulo IX do livro A pedagogia no Brasil: história e teoria, Cap. IX, SAVIANI, 
2008a, p. 119-123); f) jornada de trabalho precária e baixos salários. (SAVIANI, 2011. p. 14).

Nessa conjuntura, pode-se dizer que estes entraves expressam as fragilidades encontradas na formação de professores, uma vez que os cursos destinados a formação docente não têm oferecido os conhecimentos e habilidades consideradas necessárias ao enfrentamento das complexas atividades exigidas no âmbito escolar.

Diante desse contexto, pode-se dizer que discutir a formação inicial de professores é basilar no sentido de contextualizar a atuação desse profissional, uma vez que em sua formação ele se apropria de conhecimentos, que irão configurar o exercício do seu trabalho. Assim sendo, Saviani (2011), evidencia o fato de que a formação dos professores se dá, também, como um trabalho docente por parte dos formadores. Portanto, se as políticas educativas, como regra geral, não priorizam o provimento de condições adequadas para a realização do trabalho docente, também os cursos de formação dos professores se desenvolverão em condições insatisfatórias, o que resultará numa formação igualmente insatisfatória.

\section{OS PARADIGMAS DA FORMAÇÃO DE PROFESSORES E SUAS REPERCUSSÕES NA FORMAÇÃO DOS LICENCIANDOS}

Como a essência dos paradigmas da formação de professores definidos em cada contexto específico reflete tanto nas práticas dos professores-formadores em sala de aula, quanto nas concepções que os licenciandos constroem no decorrer de sua formação, faz se necessário destacar através de uma breve trajetória, as tendências paradigmáticas de formação oferecidas aos professores no Brasil. Nessa perspectiva, torna-se imprescindível evidenciar os modelos de formação, suas exigências e consequentemente, o papel do professor no contexto educativo.

Para tratar dos paradigmas da formação de professores no contexto brasileiro, é importante relembrar que uma das primeiras iniciativas voltadas a organização da formação de professores surgiu no final dos anos 1930, na Faculdade Nacional de Filosofia. Segundo Saviani (2009), essas iniciativas resultaram no Decreto-lei 1.190, de abril de 1939, configurando-se no "esquema 3+1" adotado para a organização dos cursos de Licenciatura e de Pedagogia da época. Assim, após três anos de formação específica em sua área, o aluno obtinha o título de bacharel e, ao realizar um ano complementar na seção de Didática, obtinha o título de Licenciado, garantindo o direito legal de lecionar no nível secundário. É importante frisar que esse modelo foi bastante criticado, justamente por separar os saberes científicos dos pedagógicos, favorecendo uma concepção simplista de que para ensinar seria necessário apenas saber o conteúdo e aplicar algumas técnicas didáticas. 
Pimenta (1997) a partir de suas análises confirma que na história da formação de professores, esses saberes têm sido trabalhados como blocos distintos e desarticulados, muita das vezes, um sobrepondo ao outro, em decorrência do status e poder que adquirem nas instituições acadêmicas.

Nessa linha de raciocínio, Brzezinski (1992) destaca que a formação nos cursos de licenciatura, particularmente no que se refere à formação pedagógica e à formação específica, é nitidamente fragmentada. Em decorrência disso, essa autora enfatiza que essa fragilidade, constituise mais numa deformação do que mesmo numa formação para a docência.

Foi nesse contexto que o paradigma da racionalidade técnica passou a imperar e organizar a estrutura da formação de professores, de modo a ser considerado como uma nova base eficiente, de controle de gastos, rápida e segura para o desenvolvimento da preparação e prática do professor. Com base nessa formação, o professor precisaria dominar técnicas para desenvolver eficientemente seu trabalho em sala de aula.

É imprescindível destacar que esse modelo de formação teve suas origens na concepção epistemológica da prática herdada do positivismo, em que a fonte do conhecimento centrava-se na razão científica. Desse modo, a razão científica foi sendo apropriada pelo sistema capitalista como uma forma de controle de poder para manter a desigualdade fortemente presente na sociedade. Sendo assim, a base do modo de produção capitalista passou a ser a racionalidade técnica sob os princípios do controle, previsão e ação eficiente. Essa inteligibilidade denominada de razão técnica própria do sistema capitalista passou a ser transposta para todas as instituições da vida social, inclusive para a instituições de ensino.

Dessa forma, o modelo da racionalidade técnica se impregnou nas bases educacionais, estruturando o currículo, a prática do professor, a organização da escola e a estrutura da formação de professores pautado no domínio de todo um arsenal técnico. Nesse contexto, o papel do professor-formador é de passiva conformidade com as recomendações práticas dos especialistas e gestores educacionais, tendo em vista a indicação de métodos e técnicas que prometiam assegurar o êxito da aprendizagem dos licenciandos em sua formação.

Nesse prisma, a prática docente passa a ser concebida como o saber fazer, que condiciona o seu agir em sala de aula. Logo, a formação para o exercício da docência, priorizava exclusivamente o domínio do conteúdo e de habilidades reducionistas, a partir do momento que se exigia do professor ao lecionar sua disciplina, o domínio de procedimentos específicos, baseado em pressupostos expressos por técnicas ou manuais que objetivavam intervenções pontuais, negando 
suas concepções e história, sua atividade intelectual de análise crítica, a partir da padronização de suas ações e reações.

Em contraposição ao modelo da racionalidade técnica surge o paradigma da racionalidade prática decorrente da análise teórica do norte-americano Donald Schön, tendo como base fundante as concepções de Dewey, que propõe uma formação profissional baseada na epistemologia da prática. De acordo com essa visão, a compreensão da dimensão prática, do fazer, da atuação em sala de aula será desenvolvida a partir da atitude do professor reflexivo. Assim, a prática passa a ser modificada à luz de circunstâncias, as quais somente podem ser "controladas" por meio de sua deliberação sobre a prática.

Pimenta (1997) analisando essa tendência que se convencionou chamar de teoria do professor reflexivo, argumenta que neste pensamento a formação de professores é entendida como autoformação, na qual as experiências e práticas desses profissionais vão se constituindo em seus saberes. Porém, em contrapartida a esse modelo, vários autores, inclusive essa autora, têm apresentado preocupações quanto ao desenvolvimento de um possível praticismo, decorrente dos estudos do professor reflexivo,

[...] para o qual bastaria a prática para a construção do saber docente; de um possível individualismo, fruto de uma reflexão em torno de si própria; de uma possível hegemonia autoritária, se se considera que a perspectiva da reflexão é suficiente para a resolução dos problemas da prática; além de um possível modismo, com uma apropriação indiscriminada e sem críticas, sem compreensão das origens e dos contextos que a geraram, o que pode levar à banalização da perspectiva da reflexão (p. 22).

Nessa perspectiva, o destaque incide sobre a prática em detrimento da teoria, que acaba ficando em segundo plano no processo formativo. Em se tratando de formação inicial de professores, a articulação da teoria e prática precisa ser o fio condutor da trajetória formativa. Assim, se entende que esta formação precisa propiciar ao licenciando a apropriação de conhecimentos teóricos e práticos que lhes deem condições de interpretar o contexto em que o cenário educacional está inserido, e de se portar com autonomia na condução de sua prática pedagógica no campo profissional.

Com esses questionamentos, não se está querendo recusar a importância de uma postura reflexiva por parte do professor, porém a crítica recai na excessiva ênfase que é atribuída a dimensão prática no exercício docente que acaba por substituir a supervalorização da teoria presente na racionalidade técnica, quando propõe uma formação técnica e mecânica, tendo em vista a quase negação dos condicionantes sociais que cercam o ato educativo. Portanto, os dois paradigmas de 
formação de professores enfatizados acima acabam, assim, convergindo, no sentido de manter a separação entre teoria e prática

Entretanto, diferentemente da passividade dos professores encontrada no modelo da racionalidade técnica, nessa visão o professor precisa questionar, refletir e constantemente examinar sua prática pedagógica cotidiana. Schön (2000) denominou essa visão de prática reflexiva ${ }^{2}$ por possibilitar aos docentes responder adequadamente às situações novas de incertezas e indefinição da ação educativa em sala de aula a partir do processo de reflexão sobre sua prática.

Na intenção de superação destes modelos, mesmo considerando a contribuição de cada um deles na formação docente, tem-se o que muitos pesquisadores vêm chamando de racionalidade crítica, que é um modelo de formação, que relaciona as dimensões teórica e prática movida por objetivos ético-políticos, por isso não mecânica ou meramente instrumental. A prática, então, é vista como a fonte da teoria, da qual se nutre como objeto de conhecimento, interpretação e transformação.

Em razão disso, Pimenta (2002) esclarece que a práxis é a atitude (teórico-prática) humana de transformação da natureza e da sociedade. Para a autora, no âmbito da educação e da condução da formação de professores tal conceito pressupõe a operacionalização de ações pautadas em uma intencionalidade de transformação da realidade imediata (a sala de aula e a escola) e do espaço social mais amplo.

Giroux (1997) discute a necessidade da formação do professor como um intelectual, crítico e transformador. Com base neste autor, um professor com estas características, passa a se reconhecer como sujeito capaz de promover mudanças, uma vez que ao manifestar-se a respeito de diferentes aspectos sociais dentro e fora da escola, também busca desenvolver seu trabalho, dando condições para que seus alunos se tornem cidadãos críticos e transformadores. Assim sendo, o trabalho do professor vai além da sala de aula, a partir do momento que ele problematiza as questões sociais e concebe a escola como um espaço de vivências democráticas para através da reflexão crítica se contrapor as perversidades do capitalismo. Logo, assumir uma postura crítica é se apropriar de mecanismos de defesa contra os processos ideológicos que estão sendo constituídos pelas ideias dominantes.

\footnotetext{
${ }^{2}$ A perspectiva da prática reflexiva se circunscreve na concepção de Schön (2000), que considera três tipos de reflexão envolvidos no trabalho docente: o primeiro, chamado de reflexão na ação; segundo, reflexão sobre a ação e o terceiro tipo reflexão sobre a reflexão na ação. Schön defende o aprender fazendo como princípio formador, pois acredita que o sujeito, pela própria experiência vivida em conhecer, apropriar-se-á verdadeiramente de conhecimentos. Defende, ainda, a reflexão como principal instrumento de apropriação de saberes necessários à docência.
} 
Diante desse contexto, considera-se então, que a racionalidade técnica, cujas raízes foram fincadas no positivismo, trouxe historicamente limites para o desenvolvimento profissional do professor e, consequentemente, para o desenvolvimento do trabalho docente, visto que as medidas que alteraram a estrutura do campo educacional têm se assentado nos princípios da produtividade, eficácia, excelência e eficiência. Eis o que se pode chamar de "herança" da racionalidade técnica impregnada, sobretudo na prática docente no contexto educacional brasileiro atual. Entretanto, em pleno século XXI esse modelo de formação, que prioriza uma concepção instrumental da ação docente em detrimento de uma prática emancipadora e que não considera o licenciando como um ser social, ainda hoje não foi totalmente superado.

\section{A FORMAÇÃO DO LICENCIANDO E SUAS IMPLICAÇÕES NA CONSTRUÇÃO DA IDENTIDADE DOCENTE}

De acordo com as análises de Pimenta (1997), a identidade é entendida como um processo de construção social de um sujeito historicamente situado. E como não é um elemento imutável, o professor constitui sua identidade por meio de sua formação escolar, da formação inicial de professores, das experiências diversas, dos processos de formação continuada, das influências sociais, dentre outros.

Com base nesse entendimento, estudar a formação inicial de professores como a primeira preparação para o exercício da docência é refletir que, nessa etapa, o licenciando mobiliza saberes a respeito da docência, que começam a se constituir mesmo antes da sua inserção na escola e que seguem em movimento ao longo de sua formação, para então, constituir, juntamente com aqueles mobilizados durante a licenciatura, seu repertório para a construção da identidade docente.

Pimenta (1997) afirma que para além da finalidade de atribuir uma habilitação legal para o exercício profissional da docência, se espera que o curso de formação inicial realmente forme o professor, ou que colabore para sua formação. Assim, espera-se que esses cursos propiciem o desenvolvimento de conhecimentos, habilidades, atitudes e valores que possibilite ao professor a construção dos saberes docentes.

Nesse prisma, a mobilização dos saberes da docência, necessários à compreensão do ensino como prática social, precisa desenvolver nos professores, a capacidade de investigar a própria atividade para, a partir dela, constituírem e transformarem a realidade, num processo contínuo de construção de suas identidades como docente. Diante desse contexto, Pimenta (1997) identifica três tipos de saberes necessários à docência: saberes da experiência; saberes do conhecimento e saberes pedagógicos. 
Segundo a autora, os licenciandos ao chegarem na formação inicial já possuem saberes a respeito do que é ser professor, advindos de suas experiências enquanto aluno, das representações e estereótipos existentes na sociedade veiculados através dos meios de comunicação, outros, porque são já professores ou exerceram o magistério. Estes saberes a autora denomina de saberes da experiência.

Para Pimenta (1997),

[...]. O desafio, então, posto aos cursos de formação inicial é o de colaborar no processo de passagem dos alunos de seu ver o professor como aluno ao seu ver-se como professor. Isto é, de constituir a sua identidade de professor. Para o que os saberes da experiência não bastam. (p. 20).

Nessa perspectiva, outros saberes que contribuem na construção da identidade dos professores dos cursos de Licenciatura são os saberes do conhecimento. Ainda segundo Pimenta (1997), o desafio é justamente possibilitar que o licenciando ao longo de sua formação inicial trabalhe os conhecimentos adquiridos, desenvolvendo habilidades para operá-los, revê-los e reconstruí-los com sabedoria. Isso implica ter a capacidade de analisá-los, confrontá-los e contextualizá-los no sentido de possibilitar-lhes o desenvolvimento da reflexão para a aquisição dos saberes necessários à permanente construção humana.

Entretanto, isso só será possível a partir do momento que as instituições de ensino e o professor-formador entenderem que conhecer algo não se reduz a informar, ou seja, que não basta expor-se aos meios de informação para adquirir conhecimento. Para conhecer se faz necessário operar com as informações para se chegar ao conhecimento. Isso implica que ao longo do processo de formação, as questões dos conhecimentos específicos de cada área sejam discutidas e contextualizadas na conjuntura da contemporaneidade, de modo que o curso de formação contribua para o processo de humanização, por meio do trabalho coletivo e interdisciplinar do licenciando com o conhecimento, numa perspectiva de inserção social crítica e transformadora.

Indo contra a fragmentação dos saberes da docência nos cursos de licenciatura, Houssaye (1995) indica como caminhos de superação, que os saberes pedagógicos, também constitutivo da identidade docente, sejam constituídos a partir das necessidades pedagógicas postas pelo real, ou seja, para além dos esquemas apriorísticos das ciências da educação. Trata-se, portanto, de reinventar os saberes pedagógicos a partir da prática social da educação. (apud PIMENTA, 1997. p. 9) 
Nesse sentido, a formação inicial, precisa propiciar ao licenciando a apropriação dos saberes da docência de forma articulada, de modo que ele se reconheça como professor e não como um especialista em sua área de atuação. Portanto, munidos desses saberes, o futuro professor no exercício de sua prática pedagógica, irá compreender como seu aluno aprende, como organizar situações de aprendizagem, o porquê de ensinar determinado conteúdo, qual a relação de sua disciplina com as demais, qual a contribuição desse conteúdo para a formação de seu aluno, que processo formativo orienta sua ação, etc. Com base nesse contexto, entende-se que para ser professor, não bastam apenas os saberes da Ciência a ser ensinada, mesmo sabendo que é uma condição necessária, porém não suficiente para o exercício da docência das áreas específicas do conhecimento.

\section{CONCLUSÃO}

Conclui-se, portanto, que diante das circunstâncias destacadas, a formação inicial de professores, mas especificamente, as licenciaturas, embora tenha se tornado uma temática central nas discussões no cenário acadêmico brasileiro e nas políticas educacionais, continuam sem alterações significativas em seu processo formativo.

Nessa direção, pode-se dizer que as configurações curriculares que a formação inicial de professores assume nas instituições encarregadas de desenvolvê-la estão diretamente conectadas com um contexto social, econômico e político que lhes rodeiam, que contagiado por valores ideológicos ligados a divergentes concepções de homem, sociedade e educação, decisivamente influencia os processos formativos, os direcionando para a apropriação de um determinado projeto de sociedade.

Por isso, enfatiza-se a necessidade não apenas de uma reformulação nos currículos dos cursos de formação de professores, mas de uma reorientação da cultura institucional e docente no interior das licenciaturas, de modo que os professores-formadores se reconheçam como professores que formam professores e não especialistas de áreas específicas.

Diante das circunstâncias, evidencia-se também a necessidade uma formação que permita a inserção do licenciando na vivência do contexto escolar durante toda formação; que articule os saberes da docência de modo que o licenciando passe a se reconhecer como professor; que possibilite a apropriação de conhecimentos teóricos e práticos que lhes deem condições de interpretar o contexto em que o cenário educacional está inserido, tomando consciência do seu papel enquanto sujeito político para conduzir suas práticas pedagógicas a partir de uma postura 
investigativa, reflexiva e crítica necessária a implementação de uma ação coletiva capaz de transformar a realidade. Somente assim, este profissional terá condições de caminhar em direção à uma prática comprometida com a construção de uma sociedade mais justa, cujo objetivo seja a formação de indivíduos emancipados. 


\section{REFERÊNCIAS}

ANTUNES, Ricardo. Os sentidos do trabalho: ensaio sobre a afirmação e a negação do trabalho. 6. ed. São Paulo: Boitempo Editorial, 2002.

BRZEZINSKI, I. Trajetória do movimento para as reformulações curriculares dos cursos de formação de profissionais da educação: do Comitê (1980) à ANFOPE (1992). Em Aberto, v. 54, n. 12, p. 75-86, 1992.

FARIA, Lenilda Rêgo Albuquerque de. As orientações educativas contra-hegemônicas das décadas de 1980 e 1990 e os rebatimentos pós-modernos na didática a partir da visão de estudiosos. 2011. 342p. Tese (Doutorado) - Faculdade de Educação da Universidade de São Paulo, 2011.

FREITAS, Helena Costa. O trabalho como princípio articulador na prática de ensino e nos estágios. 6. ed. Campinas, SP: Papirus, 1996. (Coleção Magistério: formação e trabalho pedagógico).

FREITAS, Luiz Carlos. Os reformadores empresariais da educação e a disputa pelo controle. Educ. Soc., Campinas, v. 35, n. 129, p. 1085-1114, out.-dez. 2014.

FRIGOTTO, Gaudêncio. Educação e a crise do capitalismo real. 6. ed. São Paulo: Cortez, 2010. p. $27-62$.

GIROUX, Henry. A. Os professores como intelectuais: rumo à uma pedagogia crítica da aprendizagem. Trad.: Daniel Bueno. Porto Alegre: Artmed, 1997.

LIBÂNEO, José Carlos. Reflexividade e formação de professores:outra oscilação do pensamento pedagógico brasileiro. In: PIMENTA, Selma Garrido; GHEDIN, Evandro. (Orgs.). Professor reflexivo no Brasil: gênese e crítica de um conceito. São Paulo: Cortez, 2010.

MARX, Karl. Manuscritos econômicos-filosóficos. Trad.: Jesus Ranieri. São Paulo: Boitempo Editorial, 2006.

OLIVEIRA, Dalila Andrade. A reestruturação do trabalho docente: precarização e flexibilização. Educação e Sociedade. Campinas, vol. 25, n. 89, p. 1127-1144, set./dez, 2004.

As políticas de formação e a crise da profissionalização docente: por onde passa a valorização? Educação e Sociedade. Revista Educação em Questão, Natal, v. 46, n. 32, p. 51-74, maio/ago. 2013.

PAUlO NETTO, José; BRAZ, Marcelo. Economia Política: uma introdução crítica. São Paulo: Cortez, 2006.

PIMENTA, Selma Garrido. Formação de professores: saberes da docência e identidade do professor. Revista da Faculdade de Educação, USP, v. 1. n. 1, p.72-89, jul./dez.1997.

PIMENTA, Selma Garrido. O estágio na formação de professores: unidade teoria e prática? São Paulo: Cortez, 2002.

PIMENTA, Selma Garrido. Professor reflexivo: construindo uma crítica. In: PIMENTA, Selma Garrido; GHEDIN, Evandro. (Orgs.). Professor reflexivo no Brasil: gênese e crítica de um conceito. São Paulo: Cortez, 2010.

SAVIANI, Dermeval. Trabalho e educação: fundamentos ontológicos e históricos. Revista Brasileira de Educação. v. 12, n. 34, jan/abr. 2007.

Formação de professores: aspectos históricos e teóricos do problema no contexto brasileiro. Revista Brasileira de Educação. v. 14, n. 40, jan./abr. 2009.

07-19.

Formação de professores no Brasil: dilemas e perspectivas. Poíesis Pedagógica, v. 9, n. 1, jan./jun. 2011; p.

SCHÖN, Donald. Educando o profissional reflexivo: um novo design para o ensino e a aprendizagem. Porto Alegre: Artes Médicas Sul, 2000.

SEVERINO, Antônio Joaquim. Educação, Sujeito e História. São Paulo: Olho d’Água, 2001.

. A formação e a prática do professor em face da crise atual dos paradigmas educacionais. Ciência \& Opinião, v. 1, n. 2/4, p. 15-31, 2004.

Metodologia do Trabalho Científico. São Paulo: Cortez, 2007. 


\section{RESUMO}

Este artigo tem como objetivo apresentar um estudo sobre os impasses teórico-metodológicos no campo da formação inicial de professores, visando discutir os contornos assumidos na formação dos licenciandos no contexto brasileiro atual. $O$ presente estudo trata-se de uma pesquisa bibliográfica de enfoque qualitativo, que tem como referencial teórico as análises de Antunes (2002); Faria (2011); Freitas (1996; 2014); Frigotto (2010); Libâneo (2010); Marx (2006); Oliveira (2004; 2013); Paulo Netto e Braz (2006); Pimenta (1997; 2002; 2010); Saviani (2007; 2009; 2011) e Severino (2001; 2004; 2007). O texto traz, inicialmente, uma sucinta introdução sobre a temática em questão. Na sequência, descreve a metodologia utilizada para a construção do estudo. Na continuidade, enfatiza as categorias trabalho e educação como bases ontológicas do ser social e as mudanças de sentido sob a ordem do capital. Posteriormente, faz um breve apontamento a respeito dos impactos das reformas neoliberais na formação de professores no Brasil. Em seguida, apresenta os paradigmas da formação de professores e suas implicações na formação dos licenciandos. Finaliza, apontando a importância da articulação entre os saberes da docência como base constitutiva da identidade profissional do professor.

Palavras-chave: Formação inicial de professores. Licenciando. Professor.

\section{THE INITIAL TEACHER TRAINING IN THE BRAZILIAN CONTEXT AND ITS IMPLICATIONS IN LICENSEE TRAINING}

\section{ABSTRACT}

This article aims to present a study on theoretical and methodological impasses in the field of initial teacher training, aiming to discuss the contours assumed in the training of graduates in the current Brazilian context. The present work deals with a bibliographical research of qualitative approach, that has as theoretical reference the analyzes of Antunes (2002); Faria (2011); Freitas (1996, 2014); Frigotto (2010); Libâneo (2010); Marx (2006); Oliveira (2004; 2013); Paulo Netto e Braz (2006); Pimenta (1997, 2002; 2010); Saviani $(2007,2009,2011)$ and Severino $(2001,2004,2007)$. The text initially presents a succinct introduction on the theme in question. It then describes the methodology used to construct the study. In continuity, it emphasizes the categories labor and education as the ontological bases of social being and the changes of meaning under the order of capital. Later, he briefly points out the impacts of neoliberal reforms on teacher education in Brazil. Next, it presents the paradigms of the formation of teachers and their implications in the formation of the graduates. He ends by pointing out the importance of the articulation between the teaching knowledge as the constitutive basis of the professional identity of the teacher.

Keywords: Initial teacher training. Licensing. Teacher.

Submetido em 30 de março de 2019 Aprovado em 01 de setembro de 2019 